\title{
Desafios na prática pedagógica na educação profissional em enfermagem
}

Challenges in the pedagogical practice in nursing professional education

Desafíos en la práctica pedagógica en la educación profesional en enfermería

Edilmara Gubert ${ }^{\mathrm{I}}$, Marta Lenise do Prado ${ }^{\mathrm{II}}$

\section{RESUMO}

Estudo descritivo de abordagem qualitativa, que teve por objetivo desvelar como a formação dos enfermeiros determina a sua prática pedagógica na educação profissional em enfermagem, principalmente no que se refere ao princípio da interdisciplinaridade. A coleta foi realizada por meio de entrevistas semiestruturadas e como procedimentos de análise foram adotadas as etapas de codificação aberta e axial da Teoria Fundamentada de Dados. Os resultados apontam que um dos maiores desafios está relacionado à formação inicial e permanente do educador para atuar em conformidade com os princípios propostos pela Lei de Diretrizes e Bases (LDB), especialmente a interdisciplinaridade. Conclui-se, que há ainda um distanciamento dos princípios propostos pela LDB e a prática de ensino, evidenciando a necessidade da capacitação docente para trabalhar na perspectiva da interdisciplinaridade.

Descritores: Educação em Enfermagem; Enfermagem; Educação Profissionalizante; Ensino.

\section{ABSTRACT}

Descriptive study of qualitative approach, which has as objective to expose how nurses' formation determines their pedagogic practice in professional nursing education, principally in what is referred to interdisciplinary. It was gathered the expressions of a nursing educators group of nursing middle level technical courses of Santa Catarina state. Data collection was done through semi-structured interviews and as a procedure for data analysis it was adopted the stages of the opened and axial codification of the Fundamental Data Theory. The results show that one of the greatest challenges is related to initial and permanent educators formation, to act in conformation with the proposed principles of the Directive Law and Base (DLB), especially the object of this study, the interdisciplinary. It is concluded that there is a distance to the proposed principles by DLB, and as a result it is seen the necessity of docent work capacitation in the interdisciplinary perspective.

Descriptors: Education, Nursing; Nursing; Education, Professional; Teaching.

\section{RESUMEN}

Estudio descriptivo de abordaje cualitativo, cuyo objetivo fue descubrir como la formación de enfermeros determina su práctica en la educación profesional en enfermería, especialmente en relación con el principio de la interdisciplinariedad. Los datos fueron recolectados a través de entrevistas semi-estructuradas y procedimientos de análisis como las medidas adoptadas fueron la codificación abierta y axial estructurada en la teoría basada en datos. Los resultados muestran que uno de los mayores retos es la formación inicial y permanente de los profesores para actuar de acuerdo con los principios propuestos por la Ley de Directrices y Bases (LDB), especialmente la interdisciplinariedad. La conclusión es que hay una brecha de principios propuestos por la LDB y la práctica docente, lo que apunta necesidad de formación de profesores para trabajar en una perspectiva interdisciplinario.

Descriptores: Educación en enfermería; Enfermería; Formación profesional; Enseñanza.

\footnotetext{
${ }^{\text {I }}$ Enfermeira, Mestre em Enfermagem, Coordenadora de Cursos de Formação Inicial Continuada e Educação Técnica de Nível Médio do Serviço Nacional de Aprendizagem Comercial - SENAC/SC. Florianópolis, SC, Brasil. E-mail: edilmarag@yahoo.com.br.

II Enfermeira, Doutora em Enfermagem, Pós-Doutorado pela Universidade de Barcelona, Professor Associado, Departamento de Enfermagem, Centro de Ciências da Saúde, Universidade Federal de Santa Catarina. Pesquisadora do CNPq. Florianópolis, SC, Brasil. E-mail: mprado@ccsufsc.br.
} 


\section{INTRODUÇÃO}

A Lei de Diretrizes e Bases da Educação Nacional $\operatorname{LDB}^{(1)}$ estabelece as diretrizes curriculares da educação nacional e o Parecer do Conselho Nacional de Educação CEB/CNE no $16 / 99^{(2)}$ traz os princípios da educação e dentre eles a interdisciplinaridade, a flexibilidade e a contextualização, e com eles a exigência de uma nova postura dos educadores. E o enfermeiro educador está preparado para trabalhar neste contexto e assumir este desafio?

O enfermeiro tem um obstáculo decorrente de sua formação, pois traz para sua prática docente, uma formação técnica essencialmente ligada ao cuidado, que é o seu foco de atuação. Além disso, ele aprende a profissão no lugar similar àquele que vai atuar, mas em uma situação invertida e isso pressupõe uma coerência entre o profissional que se deseja formar e como este profissional se constrói como educador ${ }^{(3)}$.

A formação docente em enfermagem, como ocorre em outras áreas profissionais, tem merecido muitas discussões e algumas pesquisas em função da constatação da necessidade de transformações filosóficas e pedagógicas que venham atender às expectativas da cultura no novo milênio, como está estabelecido na $\mathrm{LDB}^{(1)}$, que, dentre as finalidades principais, destaca a necessidade de se estimular a formação de profissionais com espírito científico e pensamento reflexivo ${ }^{(4)}$.

A perspectiva fragmentada e o currículo dissociado da realidade impossibilitam uma prática de forma integral. É exatamente aí que está a dificuldade, pois, nossa formação escolar nos ensina a separar os objetos de seu contexto e as disciplinas umas das outras, mas não nos ensina a correlacioná-los ${ }^{(5)}$.

Observa-se ainda que, com a produção de um conhecimento fragmentado, dissociado do contexto, "cria-se um conhecimento limitado, ao mesmo tempo em que se produz um mosaico de informações, de conhecimentos paralelos, desagregados uns dos outros, e até mesmo antagônicos, todos tidos como legítimas representações da realidade ${ }^{\prime \prime(6)}$.

As abordagens pedagógicas na perspectiva da interdisciplinaridade podem aproximar o educando da realidade, mas, é preciso que os enfermeiros educadores conduzam o processo de ensino e aprendizagem para que os educandos possam resolver problemas com outras áreas de conhecimento e, mais ainda, quando pertencem ao domínio interdisciplinar. É inegável que no âmbito do ensino é necessária a superação da fragmentação e a formação integral dos educandos para que possam exercer criticamente sua profissão(6).

Outro aspecto relevante é que para essa mudança, o educador precisa desvencilhar-se do velho para construir o novo e neste processo a primeira atitude é de aceitação do novo para, em seguida, rever suas atitudes sobre a realidade, estando aberto para as incertezas, reorganizando seu pensamento e sua ação. É necessário mudar a postura pedagógica que está enraizada nos educadores, mas para isso são necessárias mudanças de atitudes, estabelecendo uma nova relação pedagógica(3). O mundo do trabalho precisa de educadores transformadores, capazes não apenas de reproduzir conhecimentos prontos, mas capazes de questionar e incentivar o educando a refletir, a criar.

Observa-se a influência da formação fragmentada e disciplinar dos profissionais na sua ação, o que demanda uma atitude cada vez mais interdisciplinar. Estudos demonstram que a dificuldade de se trabalhar de forma interdisciplinar é resultado da formação educacional fragmentada, gerando sentimentos de insegurança e despreparo para uma atuação profissional gerando a necessidade de educação continuada durante o processo de trabalho como recurso o desenvolvimento da interdisciplinaridade ${ }^{(7)}$.

Assim, o presente estudo teve por objetivo, desvelar como a formação dos enfermeiros determina a sua prática pedagógica na educação profissional e quais os desafios a vencer para colocá-la em prática.

\section{PERCURSO METODOLÓGICO}

Trata-se de um estudo descritivo, com abordagem qualitativa, desenvolvido com a participação de vinte enfermeiros educadores de cursos Técnicos de Enfermagem do Estado de Santa Catarina, sendo dez enfermeiros educadores de escolas públicas e dez de escolas privadas, conforme Quadro 1. 
Quadro 1: Perfil dos Enfermeiros Educadores entrevistados (Santa Catarina, SC, 2009).

\begin{tabular}{|c|c|c|c|c|}
\hline $\mathbf{N}$ & CODINOME & SEXO & LOCAL DE ORIGEM & NATUREZA DA ESCOLA \\
\hline 01 & Enfermeiro educador $\mathrm{A}$ & Feminino & Blumenau & Pública \\
\hline 02 & Enfermeiro educador $\mathrm{B}$ & Masculino & Joinville & Privada \\
\hline 03 & Enfermeiro educador $\mathrm{C}$ & Feminino & Florianópolis & Pública \\
\hline 04 & Enfermeiro educador $\mathrm{D}$ & Feminino & Brusque & Privada \\
\hline 05 & Enfermeiro educador $\mathrm{E}$ & Feminino & Joinville & Privada \\
\hline 06 & Enfermeiro educador $\mathrm{F}$ & Feminino & Blumenau & Pública \\
\hline 07 & Enfermeiro educador $\mathrm{G}$ & Feminino & Lages & Privada \\
\hline 08 & Enfermeiro educador I & Feminino & Florianópolis & Pública \\
\hline 09 & Enfermeiro educador $\mathrm{J}$ & Feminino & Blumenau & Pública \\
\hline 10 & Enfermeiro educador $\mathrm{K}$ & Feminino & Florianópolis & Privada \\
\hline 11 & Enfermeiro educador $\mathrm{L}$ & Feminino & Concórdia & Privada \\
\hline 12 & Enfermeiro educador $M$ & Feminino & Joinville & Pública \\
\hline 13 & Enfermeiro educador $\mathrm{N}$ & Feminino & Concórdia & Privada \\
\hline 14 & Enfermeiro educador $\mathrm{O}$ & Masculino & Joinville & Pública \\
\hline 15 & Enfermeiro educador $\mathrm{P}$ & Masculino & Joinville & Privada \\
\hline 16 & Enfermeiro educador $\mathrm{Q}$ & Feminino & Brusque & Privada \\
\hline 17 & Enfermeiro educador $\mathrm{R}$ & Feminino & Florianópolis & Pública \\
\hline 18 & Enfermeiro educador $\mathrm{S}$ & Feminino & Florianópolis & Pública \\
\hline 19 & Enfermeiro educador $\mathrm{T}$ & Masculino & Florianópolis & Pública \\
\hline 20 & Enfermeiro educador $U$ & Feminino & Blumenau & Privada \\
\hline
\end{tabular}

A composição da amostragem foi do tipo nominal ou "bola de neve", ou seja, um grupo inicial de participantes é selecionado aleatoriamente e estes elementos, após terem sido entrevistados, indicam outros sujeitos para participação na pesquisa ${ }^{(8)}$.

O período de coleta dos dados foi de abril a julho de 2009. A escolha do local ficou a critério dos participantes do estudo. Foram definidos como critérios de inclusão: Enfermeiros Educadores que atuassem em somente uma escola de Educação Profissional desta natureza e que aceitassem participar do estudo.

A coleta de dados foi realizada por meio da entrevista semiestruturada, que seguiu um roteiro préestabelecido, com questões relacionadas à atuação diante dos princípios propostos pelo Parecer CNE/CEB $n^{\circ} 16 / 99^{(2)}$, estratégias e cenários de aprendizagem utilizados, concepção de interdisciplinaridade, atitudes e dificuldades para colocá-la em prática. 0 dimensionamento do número de participantes seguiu o critério de saturação dos dados, que significa "o conhecimento formado pelo pesquisador, no campo, de que conseguiu compreender a lógica interna do grupo ou da coletividade em estudo"(9). A entrevista semiestruturada que é "acima de tudo uma conversa a dois, ou entre vários interlocutores, realizada por iniciativa do entrevistador, destinadas a construir informações pertinentes para um objeto de pesquisa, e abordagem pelo entrevistador de temas igualmente pertinentes tendo em vista o objetivo" ${ }^{\prime(9)}$.

A aceitação dos participantes foi efetivada com a leitura e assinatura do Termo de Consentimento Livre e Esclarecido. Foram respeitados os princípios éticos da pesquisa envolvendo seres humanos, conforme a Resolução n 196/96 e o projeto de pesquisa foi aprovado pelo Comitê de Ética da Universidade Federal de Santa Catarina (Certificado n³41 de 15/08/2008).

Para análise do material empírico das entrevistas, inicialmente, realizou-se a transcrição do material gravado em audiodigital. Como procedimento de análise dos dados utilizou-se as etapas de codificação aberta e axial da Teoria Fundamentada em Dados - Grounded Theory. A Grounded Theory propõe o ordenamento conceitual que é a organização de dados em esquema de classificatório, por categoria e classificação segundo suas propriedades e dimensões, seguidas de descrições para elucidar estas categorias ${ }^{(10)}$.

Inicialmente foi feita a análise detalhada linha a linha, por meio da codificação aberta. No processo de codificação foram recortadas as unidades de análise e os dados foram agrupados em categorias e subcategorias a partir de um grande tema.

A codificação axial refere-se ao processo de 
relacionar categorias às suas subcategorias. É axial porque a codificação ocorre ao redor de uma categoria e enlaça as subcategorias em relação as suas dimensões $^{(10)}$.

\section{RESULTADOS E DISCUSSÃO}

Após leitura dos dados coletados, a análise dos dados apontou para a preocupação dos enfermeiros no que tange a sua formação pedagógica dando origem ao tema "A Formação Inicial e Permanente do Enfermeiro
Educador", com duas categorias:

I. A prática pedagógica do enfermeiro é determinada pela sua formação técnica;

II. A capacitação pedagógica do enfermeiro educador como instrumentalização para o seu fazer pedagógico.

Cada uma das categorias gerou subcategorias que estão apresentadas a seguir:

Figura 1: Tema, Categorias e Subcategorias (Santa Catarina, SC, 2009).

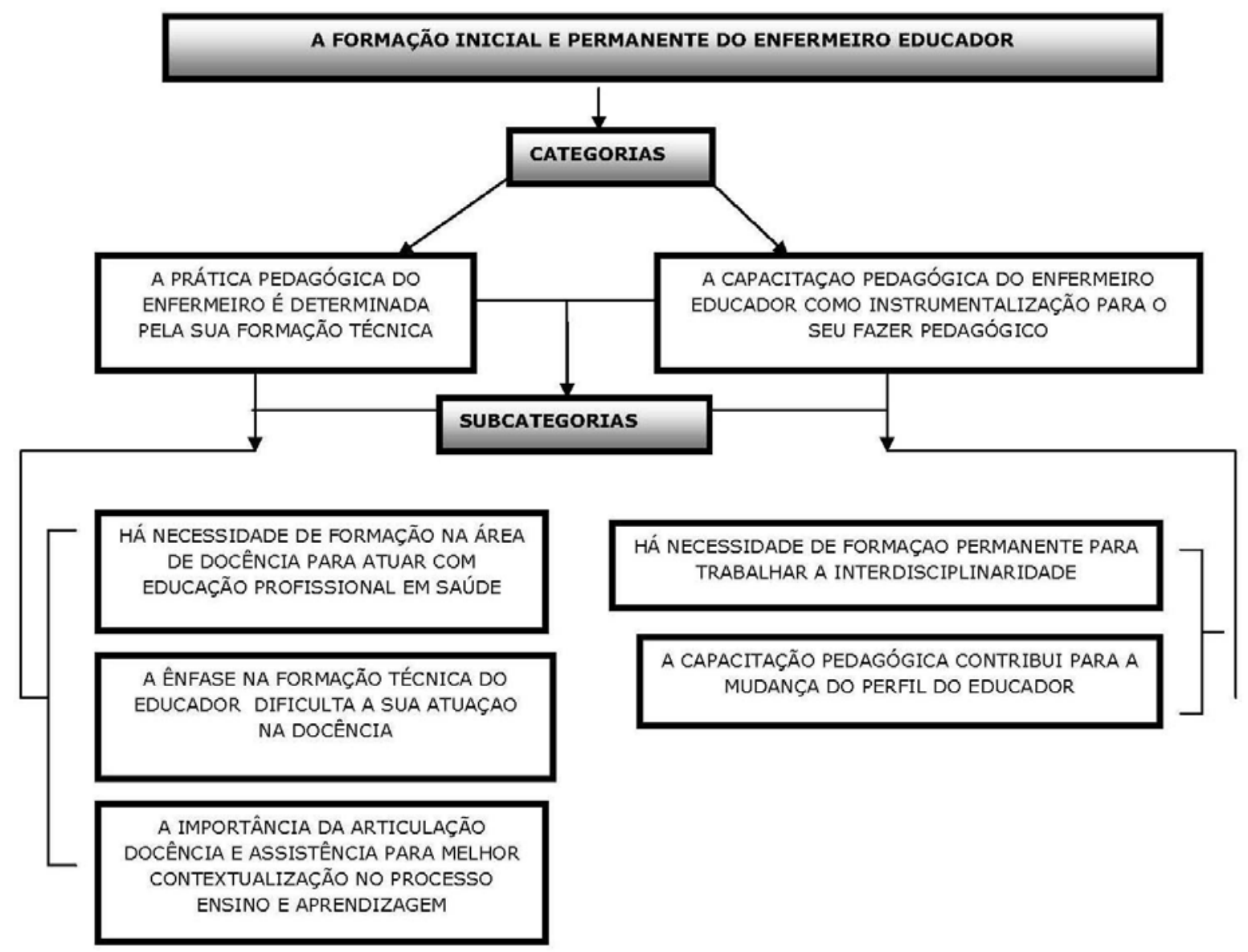

Categoria I - "A prática pedagógica do enfermeiro é determinada pela sua formação técnica":

Os conceitos relacionados pelos enfermeiros educadores foram agrupados em três subcategorias, sendo:

Há necessidade de formação na área de docência para atuar com educação profissional em saúde

Os enfermeiros educadores relacionaram a influência da formação profissional tradicional em sua prática docente. A configuração do ensino em disciplinas estanques, fragmentadas e descontextualizadas, de repasse de conteúdos, é um obstáculo para que se consiga transpor a prática tradicional.

As Diretrizes Curriculares para a Graduação em Enfermagem ${ }^{(11)}$ trazem alguns princípios pedagógicos dentre eles: a formação centrada no aluno e o professor como facilitador; a formação generalista, humanista, crítica e reflexiva; a pedagogia das competências; o aprender a aprender; a flexibilidade curricular; a questão da pesquisa na graduação em enfermagem; o Sistema Único de Saúde como foco da formação e outro aspecto 
abordado é referente à formação para a licenciatura. Entretanto, os cursos de graduação em enfermagem não formam o profissional enfermeiro para o ensino da enfermagem, ou seja, apresentam deficiências na formação de profissionais enfermeiros para a atividade docente, uma vez que estão pautados na formação norteada pelo modelo tecnicista e hospitalocêntrico.

A inexistência de disciplinas de cunho pedagógico, que envolvam o processo de aprendizagem embasado por teorias cognitivas sustentáveis, resulta em profissionais altamente preparados para o exercício de suas especialidades, sem atentar para a continuidade neste processo $^{(12)}$.

Além disso, o enfermeiro educador transfere para sua prática docente a forma como vivenciou a sua própria formação. E é um ponto comum entre os enfermeiros educadores o reflexo desta formação tradicional na sua prática pedagógica:

[...] minha formação foi numa perspectiva tradicional, bancária, de repasse de conteúdo apenas. [...] somos resultado de um ensino tradicional de repasse de conteúdo e memorização para as provas/avaliações. (Enfermeiro educador $U$ )

Primeiramente eu acho que é a questão de como fomos educados, que acaba dificultando porque muitas vezes eu acabo tentando passar o conhecimento da mesma forma que este me foi passado. Eu pelo menos aprendi tudo muito dividido. Eu aprendi a Matemática e depois aprendi só a Física e eu não via como as duas poderiam se encontrar. E eu aprendi o Português e não sabia também onde ele se encaixava em tudo isso que eu estava aprendendo e onde eu poderia aplicar isso na minha vida realmente. (Enfermeiro educador $K$ )

A compartimentalização disciplinar traz consequências negativas no mundo onde se enfatiza a integralidade, a totalidade. Com a fragmentação, o educando não faz uma relação dos saberes com a realidade e considerando essas experiências, "surge a necessidade de se refletir sobre a lógica da organização disciplinar dos currículos para as graduações na área da saúde, como modo de criticá-la e transpô-la, na perspectiva de se desenharem novos sentidos para a formação"(13).

Os enfermeiros educadores relacionam ainda a dificuldade da mudança de atitudes para a inovação nesta perspectiva.
[...] fomos formados por uma escola tradicional, dentro de uma metodologia tradicional e ter que sair daquele teu cantinho já firmado e que te dá segurança, e buscar coisa nova é complicado. (Enfermeiro educador $\mathrm{F}$ )

Diante destas limitações observamos os desafios do educador e percebemos também a dificuldade de como idealizar uma atenção integral considerando que ainda a formação está fragmentada. Observa-se que a prática docente ainda precisa mudar para atender a estes princípios propostos pela $\operatorname{LDB}^{(1)}$, e que os enfermeiros educadores têm esta percepção:

Eu queria muito que existissem mudanças na prática, mas no fundo, sabemos que estão a passos muitos lentos e que mudou muito pouco na prática, porque ainda há uma resistência. (Enfermeiro educador $S$ )

Na verdade eu estudei num currículo integrado e como resultado observa-se que a prática pedagógica do educador permanece a mesma do estilo tradicional. Então, algumas coisas tentamos mudar, mas é um processo difícil. (Enfermeiro educador J)

É necessário que o enfermeiro educador tenha uma formação na área de docência para atuar com Educação Profissional, para nortear o seu fazer pedagógico. Observa-se a partir das Diretrizes Curriculares, que a formação de professores passou a ser regida por uma legislação própria que desarticulava a licenciatura de todos os cursos de graduação que também formassem professores. Entretanto, nas diretrizes curriculares da enfermagem a questão do ensino manteve os conteúdos pertinentes à formação pedagógica do enfermeiro, independente da licenciatura. Porém, observa-se que há proximidades e distanciamentos do texto legal, ou seja, algumas escolas/cursos têm inserido disciplinas com conteúdos pedagógicos e outros contemplam em seu perfil/objetivos/áreas, a dimensão pedagógica sem, contudo, inserir nenhum conteúdo/disciplina/módulo que aborde esta questão, porém apenas para atender o texto legal, sem preocupar-se com os perfis dos profissionais que desejam formar ${ }^{(14)}$.

Alguns enfermeiros educadores reconhecem a importância da formação da docência para uma melhor atuação e melhoria no processo ensino e aprendizagem:

Como eu queria a área da docência eu senti esta necessidade e então fiz a licenciatura para suprir esta 
lacuna e, além disso, a Psicopedagogia para compreender este processo maior da pedagogia em si. [...] A maioria dos educadores que estão na Educação profissional são educadores recém-formados ou até com tempo de formação, mas com experiência assistencial. São poucos os educadores que tem a docência associada à assistência. Penso que as capacitações ou mesmo as licenciaturas podem fazer com que o educador pense mais neste processo de ensino e aprendizagem e o veja em outra dimensão. (Enfermeiro educador $C$ )

A licenciatura vai te dar uma base, vai te ajudar muito em sala de aula, ela te mostra os aspectos pedagógicos desenvolvidos, a legislação, a LDB. Ela te norteia e isso fica muito mais fácil depois na tua prática profissional, na educação, no ensino e até mesmo em uma pesquisa. (Enfermeiro educador T)

A ênfase na formação técnica do enfermeiro educador dificulta a sua atuação na docência

A ênfase na formação técnica, centrada na atuação assistencial, é também percebida como um limitador na atuação docente. O processo de ensinar e aprender em saúde, de modo geral apresenta uma supervalorização da técnica, num paradigma biologicista e intervencionista. Neste cenário, outras competências, como a de educador, ficam em segundo plano, como aparece nas falas a seguir:

Existe uma dificuldade grande de nossos docentes porque eles são técnicos e a formação deles é para serem técnicos assistenciais e não docentes. A maioria dos educadores que entraram para dar aula no Técnico em Enfermagem não tem licenciatura, são raros os que têm licenciatura e uma visão na área de educação. (Enfermeiro educador $C$ )

[...] eu fui formada para a questão do cuidado, para a questão prática e não para lecionar. (Enfermeiro educador $K$ )

Pelas falas, fica evidente, a necessidade de instrumentalização do enfermeiro educador para que tenha acesso a um referencial teórico-metodológico visando uma práxis transformadora. O currículo de formação dos enfermeiros tem foco no cuidar, inclusive na aprendizagem de processos assistenciais.

Observa-se no ensino da graduação que os desenhos dos currículos ainda estão centrados na formação técnica, determinada pela racionalidade biomédica e dirigida para o alcance de objetivos finais. A formação superior em Enfermagem ainda mantém como resultado forte a preocupação com o desenvolvimento de habilidades, de destrezas e execução do cuidado e assim a aprendizagem é percebida como uma simples aquisição, retenção, acumulação e reprodução de informação, tendo a visão de educação como o repasse do conhecimento acabado em si mesmo ${ }^{(15)}$.

\section{A importância da articulação docência e assistência para melhor contextualização no processo ensino e aprendizagem}

A integração docente assistencial agrega qualidade no processo de formação, pois estas práticas pressupõem a integração dos educandos às equipes de trabalho em saúde para o desenvolvimento de ações voltadas para a realidade da comunidade. Essa perspectiva favorece a resolução/enfrentamento de problemas, evitando a dicotomia entre teoria e prática e promovendo a interdisciplinaridade. Segundo os enfermeiros educadores esta articulação facilita a contextualização no processo ensino aprendizagem:

Então eu procuro trabalhar as aulas no contexto da assistência e também trabalhando as questões pedagógicas para que os alunos compreendam melhor como vai se dar esta assistência, juntando experiência da docência e a experiência da assistência. (Enfermeiro educador $C$ )

[...] procuramos buscar no educador que ele tenha experiência no trabalho para que ele possa contextualizar. (Enfermeiro educador $F$ )

A articulação entre instituições de ensino e de serviço traz vantagens tanto para a formação quanto para a assistência. De um lado promove/favorece a construção do conhecimento ancorado na realidade concreta das práticas de saúde e de outro promove transformações nas práticas, a partir da inserção crítica e comprometida dos educandos e educadores ${ }^{(16)}$.

Articular a educação e a saúde é um desafio, pois é necessário criar e proporcionar interfaces entre distintos saberes e poderes podem, gerando oportunidades de aprofundamento dos diálogos disciplinares e de alternativas metodológicas e, consequentemente, a renovação de saberes e práticas na saúde.

Observa-se nesta categoria a influência que a educação tradicional tem sobre a atuação como 
enfermeiro educador e a importância da formação para o exercício da ação docente. Se a interdisciplinaridade visa superar, a fragmentação do real em compartimentos estanques, isso exige uma partilha de saberes, situando as informações que o educador traz num contexto para que façam sentido para o educando. E o enfermeiro educador deve estar instrumentalizado para trabalhar nesta nova proposta.

Portanto, uma das grandes dificuldades na atuação docente é em decorrência da formação do enfermeiro, uma formação fragmentada e descontextualizada. Embora as diretrizes curriculares emanadas pela LDB, forneçam a cada área de formação profissional as bases para o exercício da profissão, definindo o perfil e competências a serem alcançados, ressaltando a necessidade da flexibilização dos currículos de graduação, de forma a permitir projetos pedagógicos inovadores, formando pessoas mais críticas, reflexivas, ativas, dinâmicas, adaptáveis às demandas do mundo do trabalho, ainda existem lacunas na formação em relação a esta questão(4).

É um desafio trabalhar na perspectiva da interdisciplinaridade, pois os educadores foram formados numa perspectiva tradicional onde as disciplinas eram organizadas, mas não interagiam ou se comunicavam entre si. Os educandos, por sua vez, tinham a função de estabelecer um vinculo entre os fragmentos de conhecimento e torná-los significativos, acarretando uma compreensão bastante limitada do todo, onde não havia integração de saberes e de pessoas.

Ser educador na perspectiva da interdisciplinaridade é ter competência técnica e fundamentação destes saberes, mas acima de tudo atitudes: de flexibilidade e humildade, é construir com o outro a base do conhecimento; interagir com o outro; ir além do espaço da sala de aula superando os limites do saber escolar; estimular a critica, a reflexão; mostrar o caminho para o educando construir os saberes; propiciar condições para uma aprendizagem significativa e que efetivamente possa ser útil para a realidade. É compartilhar conhecimentos, ações e projetos baseados no diálogo. É fundamental que o educador seja capaz de conduzir o processo, mas acima de tudo adquira a sabedoria da espera, para que possa ver no educando aquilo que nem mesmo ele viu, ou leu, ou aprendeu, ou produziu ${ }^{(17)}$.

Se estabelecermos um perfil para o educando e para o futuro profissional, onde este estará articulando e mobilizando saberes na prática, necessitamos que o enfermeiro educador viabilize possibilidades e estratégias que propiciem esta formação. Para isso os educadores também devem mudar seu perfil: o de educadores que depositam conteúdos nas mentes dos educandos os quais não veem significado ou não relacionam com a realidade para educadores que insiram os educandos no contexto, tornando-o participativo e crítico; de educadores que atuam numa disciplinarização linear e sequencial para uma proposta de integração dos saberes. A escola precisa repensar que profissional deseja formar para posteriormente definir a concepção pedagógica que adotará, assumindo este compromisso em seu projeto pedagógico, centrado nos princípios da $\mathrm{LDB}^{(1)}$ preocupando-se na formação permanente do enfermeiro educador.

Modificar este contexto significa que são necessárias reformas educativas e propostas de mudanças na formação de professores ${ }^{(18)}$. Um novo espaço se forma em relação à organização escolar, onde é necessário um trabalho mais coletivo, uma maior integração e diálogo. Uma organização com novas concepções de currículo, formação, educação, sociedade e de sujeito da educação. As autoras reafirmam ainda que "a prática docente na formação inicial e na continuada necessita ser transformada em objeto de estudo, investigação, reflexão e teorização que supere práticas fragmentárias, descontextualizadas e desconectadas da realidade. A avaliação das práticas deve se processar sob critérios epistemológicos que assegurem criticidade das decisões tomadas ou a tomar e não se tornem discussões vazias focalizando superficialmente a prática pela prática"(18).

Portanto, a formação inicial pode ser o espaço para o intercâmbio de experiências no campo da educação profissional e para uma reflexão pedagógica sobre a prática docente nesta área.

\section{Categoria II: "A capacitação pedagógica do enfermeiro educador como instrumentalização para o seu fazer pedagógico"}

Agrupada em duas subcategorias, descritas a seguir:

\section{Há necessidade de formação permanente para trabalhar a interdisciplinaridade.}

Com a mudança dos currículos novos desafios devem ser assumidos pelos educadores. Novas práticas pedagógicas, a organização no interior da escola, novas situações de aprendizagem atendendo a heterogeneidade dos educandos, a cooperação docente 
ao invés do individualismo, são características de um educador nesta estrutura atual. A educação permanente dos enfermeiros educadores não deve limitar-se a adoção de estratégias pedagógicas que não correspondem a sua realidade ou a dos educandos. Entretanto, faz-se necessário uma retroalimentação do corpo docente para trabalhar nesta perspectiva e os próprios enfermeiros educadores reiteram esta necessidade:

Eu acredito que é necessária capacitação, além de estar vivenciando essas novas metodologias, estar constantemente sendo instrumentalizado para realização do processo. O educador não faz porque ele não quer $e$ sim porque não tem conhecimento da importância daquilo no processo de formação. O educador que não é formado nesta área não tem esta amplitude, conhecimentos e uma base. [...] é importante dar-lhe subsídios por meio da capacitação e este educador tem que estar mais aberto, mais motivado para realizar seu trabalho. E o educando deve conhecer este processo também e este diálogo deve ser muito transparente. Ele deve saber o que está ocorrendo, as mudanças, para que ele possa aproveitar este processo para sua melhoria. Docente e discente devem trabalhar em conjunto. (Enfermeiro educador C)

[...] um dos pontos primordiais seria a capacitação para uma ação coesa. Ainda vejo que isso é um dos entraves que poderia ser melhorado. (Enfermeiro educador $R$ ) É necessário o preparo docente para essa situação e contextualizar a realidade com o educando, trazer situações práticas, a realidade da saúde brasileira, trazer muito a questão do sistema único de saúde, que isso não é uma história é a nossa vivência. (Enfermeiro educador U)

A formação permanente estimula a adoção de novas estratégias de ensino e é uma alternativa para muni-los de ferramentas, objetivando a construção do conhecimento, as conexões entre as disciplinas, o desenvolvimento da consciência crítica e a reflexão, numa aprendizagem significativa:

O Programa de Desenvolvimento de Educadores nos trouxe essa forma lúdica, essa forma de pensar e interagir na sala de aula, fazer as aulas mais agradáveis. [...] Nas oficinas de capacitação nos dão idéias maravilhosas, mas para colocar em prática, para preparar um cartaz, um jogo, uma metodologia, precisamos de tempo e todos nós trabalhamos em outras atividades fora. Já discutimos sobre esta necessidade de estar junto, interagindo com o grupo, com os colegas e conhecendo também um pouco mais o a instituição. (Enfermeiro educador B)

O uso de metodologias diversificadas, propostas que contextualizem os temas com as práticas, com a realidade e o desenvolvimento de um espaço de aprendizagem que valorize os saberes e as trocas, pode possibilitar mudanças no fazer pedagógico, desenvolvendo cidadãos críticos, autônomos, reflexivos e competentes.

Observam-se em alguns discursos que algumas escolas promovem a formação permanente dos enfermeiros educadores, utilizando estratégias diversas como encontros, oficinas de capacitação pedagógica, incentivo às leituras, reuniões. O preparo do enfermeiro educador é necessário não apenas para instrumentalização técnica, mas para uma reflexão critica da realidade e das concepções que tem orientado suas práticas pedagógicas. E a escola deve propor em seu projeto institucional a formação permanente do enfermeiro educador. Pensar no processo ensino e aprendizagem é pensar também na instrumentalização teórica e metodológica. Além disso, são espaços coletivos de interação, de trocas, momentos de compartilhar experiências e de aprender com o outro, resgatando alguns componentes da interdisciplinaridade ${ }^{(17)}$. E os educadores reforçam a importância da formação permanente nas escolas:

A coordenadora educacional acabou organizando, planejando oficinas de multimídia, oficinas de planejamento, oficinas de avaliação, oficinas de dinâmicas de grupo para podermos estar sempre nos reciclando e até incluir os novos orientadores para que eles possam conhecer a nossa metodologia e se mantenham atualizados. E paralelo a isso estamos sempre tentando fazer leituras nesta área, tentar cada vez mais trazer subsídios. (Enfermeiro educador $D$ )

Fizemos uma capacitação didático-pedagógica que inclui a coordenação técnica e a coordenação pedagógica do curso. Então todos os educadores envolvidos nos cursos fazem essa capacitação desde o início. O objetivo é estar combinando as bases tecnológicas de acordo com a afinidade de cada educador e estar trocando também as 
informações. (Enfermeiro educador J)

A formação permanente pode proporcionar estratégias para a transformação do processo ensino e aprendizagem. E o aprender é um processo que somente ocorre se houver interação entre informações e se o educando apropriar-se delas configurando-as em significados.

Estudo aponta que o exercício da docência exige não só um amplo lastro de saberes diversificados, mas, sobretudo, uma aprendizagem contínua, considerada para as entrevistadas como fundamental na carreira profissional, alicerçada pelo aporte de saberes do professor, reafirmando a importância de mediar a articulação teórico/prática ${ }^{(19)}$. Segundo a autora, a necessidade de uma formação específica passa, também, pela iniciativa dos educadores em buscar conhecimentos por meio de cursos de formação continuada, trocas de experiências entre os pares, e preparo teórico e instrumental para atuar em sala de aula, para que se percebam como sujeitos do processo ensino e aprendizagem, demonstrando atitude ativa e reflexiva sobre a prática pedagógica que desenvolvem ${ }^{(19)}$.

\section{A capacitação pedagógica contribui para a mudança do perfil do enfermeiro educador.}

Alguns enfermeiros educadores percebem, a partir da capacitação, a mudança no papel do educador, como mediador/facilitador do processo ensino e aprendizagem, na utilização de estratégias que articulam os saberes, que privilegiem o diálogo, a interação, as experiências do educando, e a partir destas representações dos educandos pode-se construir novos conhecimentos. $E$ trabalhar na perspectiva da interdisciplinaridade pressupõe esta troca.

Nós tivemos essa capacitação desenvolvidas, principalmente, em cima do saber, do saber fazer, do ser, fazendo exercícios, desenvolvendo o que era competência, o que era atitude, o que era habilidade, que teríamos que desenvolver e tentando conscientizar o educador que não era somente repassar o conhecimento, mas tínhamos que conjugar. Então seríamos em alguns momentos um facilitador, contribuindo na construção do conhecimento do educando. (Enfermeiro educador $L$ ) Na Unidade que eu trabalho estamos numa caminhada legal, mas é em função de toda a preparação da escola. E quando você faz mudança de comportamento? Quando você adquire novos conhecimentos e quando estes conhecimentos tem significado e aí tudo flui de uma forma mais tranquila. (Enfermeiro educador $G$ )

Um estudo revela que um programa de formação contínua dentro da própria instituição contribui para a aplicação da interdisciplinaridade na prática pedagógica(20).

A interdisciplinaridade implica em um novo tipo de educador, mais flexível e mediador na construção do conhecimento para que o educandos se apropriem do conhecimento a partir da ação, reflexão, ação. Exige que o educador supere a prática individual e trabalhe no coletivo em busca de um esforço integrado para um objetivo comum: a construção do conhecimento. A formação de um educando critico reflexivo, exige um trabalho mais coletivo. Este perfil é definido pelos próprios educadores:

O educador ele é mais um mediador do que um poço de sabedoria. Então ele vai trocar mais informações e construir com aquilo que os educandos trazem e também considerar o que eles sabem. Eu acho que é nesse sentido. (Enfermeiro educador $\mathrm{J}$ )

Neste método nós somos mediadores. Livros e coisas prontas não nos interessam tanto. (Enfermeiro educador I)

O educador não domina mais o conhecimento, nós orientamos e temos que assumir esta questão de orientar e construir coletivamente. (Enfermeiro educador S)

O educador quando ele está em sala de aula: ele tem que escutar o educando, ele tem que propiciar que o educando reflita, que ele seja crítico, porque em uma estrutura tradicional não permitimos que o educando fale, que ele seja crítico. (Enfermeiro educador J)

O enfermeiro-educador é um mediador, um organizador do tempo, do espaço, das atividades, do diaa-dia do educando em seu processo de construção do conhecimento. É ele quem cria e recria sua proposta político pedagógica, e para que ela seja concreta, crítica, o educador deve ter competência técnica e pedagógica. A mediação da aprendizagem é um trabalho complexo, fundamentado na reflexão e no planejamento e que pode garantir uma maior autonomia do educando em relação ao seu aprendizado.

Concluindo esta categoria, observa-se que uma 
instituição que deseja implementar a interdisciplinaridade precisa passar por uma reestruturação no processo de capacitação de seu pessoal docente, buscando conduzir o projeto interdisciplinar. Um projeto de capacitação docente na perspectiva da interdisciplinaridade implica em: desenvolver o engajamento do educador mesmo que sua formação tenha sido fragmentada; favorecer condições para que compreenda a aprendizagem do educando, propiciar formas de diálogo e condições de troca com outras disciplinas. Isso parece difícil, considerando que a formação do enfermeiro educador foi na contramão desta proposta, mas com isso haverá uma redefinição da práxis a partir de um investimento no trabalho coletivo $^{(17)}$.

A aprendizagem se torna mais significativa se estes educandos são motivados a construir seus saberes a partir de conhecimentos prévios, e assim conseguem ver significado nestes saberes adquiridos. Assim, o enfermeiro educador ao exercer a prática pedagógica reflexiva necessita ultrapassar os limites da sala de aula. Nesse sentido, as atividades devem ser planejadas para uma contextualização e aplicabilidade dos saberes na realidade, visando desenvolver a consciência crítica dos educandos dando significado a este aprendizado. Certamente trará como consequência, um educando com uma postura mais ativa, criativa, autônoma e ciente de suas responsabilidades e condições como cidadão.

É necessário que o educador considere a legislação da Educação Profissional, dentre elas os princípios contemplados na Lei de Diretrizes e Bases, basicamente a interdisciplinaridade, tema deste estudo, para assim atingir o seu objetivo que é a formação consciente e crítica do cidadão e do profissional que atua e interage no contexto social, envolvendo dimensões epistemológicas, éticas e políticas.

\section{CONSIDERAÇÕES FINAIS}

A partir da análise dos dados e considerando os objetivos propostos neste estudo, os resultados demonstraram que um dos maiores desafios está relacionado à formação dos enfermeiros educadores, principalmente atendendo aos preceitos preconizados pela $\mathrm{LDB}^{(1)}$ e Parecer CNE/CEB $\mathrm{n}^{\circ} 16 / 99^{(2)}$, dentre eles a interdisciplinaridade, que propõe um avanço em relação ao ensino tradicional, com base na reflexão crítica sobre a própria estrutura do conhecimento, visando superar a fragmentação.
A formação inicial e permanente é condição para que - educador possa modificar sua prática pedagógica, entretanto, a flexibilidade é o primeiro passo para a mudança, pois é necessário romper barreiras, conceitos, paradigmas; é necessário transcender da postura tradicional, exercitando a aceitação de novas ideais; é necessário envolvimento e comprometimento com o processo, com o contexto.

Observa-se ainda a importância da capacitação pedagógica do enfermeiro em sua formação inicial, aliado aos processos de formação permanente para os educadores nos projetos pedagógicos das escolas. Como se espera que os educadores preparem profissionais (e sejam educadores) competentes, críticos, criativos, inovadores, e que possam enfrentar os desafios do mundo do trabalho se não estiverem instrumentalizados para esta ação? Sabe-se que isso pode ter um reflexo no perfil de saída do egresso do curso Técnico de Enfermagem.

A interdisciplinaridade implica em um novo tipo de educador, mais flexível e mediador na construção do conhecimento para que o educandos se apropriem do conhecimento a partir da ação, reflexão, ação. Exige que o educador supere a prática individual e trabalhe no coletivo. Isso pressupõe planejamento e ação coletivos envolvendo pactuação de ações e projetos visando a interligação e construção dos saberes.

O enfermeiro educador precisa ter uma postura mais critica e reflexiva, para poder intervir na realidade, apropriando-se de conhecimentos a partir desta ação. É necessário que utilize estratégias que favoreçam a aprendizagem a partir dos conhecimentos prévios dos educandos, relacionando estes saberes a outros e contextualizando com a prática.

Os resultados desse estudo põem em destaque que os enfermeiros educadores reconhecem a necessidade de sólida formação pedagógica para a superação dos desafios na implementação da interdisciplinaridade na formação profissional de enfermagem. Diante do quadro que se estabelece na Educação profissional e da complexidade do mundo do trabalho que a cada dia se acentua frente aos avanços tecnológicos, a formação inicial docente na Educação Profissional certamente é uma lacuna que somente uma Política Pública poderá suprir, favorecendo assim sua expansão.

Concluindo, a formação inicial tem um papel bastante relevante na educação profissional, pois além de favorecer uma formação consistente, fundamentada e 
crítica, instrumentaliza o professor para desenvolvimento da proposta conforme a determinação da LDB facilita a sua prática pedagógica para que utilize estratégias que envolvam o educando num papel ativo, tornando a aprendizagem significativa para o educando que terá como fazer as conexões entre os saberes.

Somente a partir de uma sólida formação pedagógica, o profissional estará instrumentalizado e poderá ressignificar o processo educativo como agente de transformação. Assim, poderá estar munido de ferramentas para elaborar estratégias e buscar formas criativas de ensino e aprendizagem, considerando a heterogeneidade dos educandos e desenvolvendo um trabalho integrado e interdisciplinar, contextualizado no mundo do trabalho. Esta formação além de refletir na escola, no educando, no mundo do trabalho, refletirá no próprio educador que se sentirá mais seguro para trabalhar diante das incertezas do mundo contemporâneo, e também mais valorizado.

Observa-se que embora algumas escolas realizem atividades de educação permanente dos enfermeiros

\section{REFERÊNCIAS}

1. Ministério da Educação; Conselho Nacional de Educação. Lei no 9.394/96 - Dispõe sobre a lei de diretrizes e bases da educação nacional. Brasília (Brasil): Ministério da Educação; 1996.

2. Ministério da Educação, Conselho Nacional de Educação. Parecer CEB/CNE no 16/1999 - Trata das diretrizes curriculares para a educação profissional de nível técnico. Brasília (Brasil): Ministério da Educação; 1999.

3. Reibnitz KS, Prado ML. Inovação e Educação em Enfermagem. Florianópolis: Cidade Futura; 2006.

4. Faria JIL, Casagrande LDR. A educação para o século XXI. Rev Lat Am Enfermagem. 2004;12(5):821-7.

5. Morin E. A cabeça bem-feita: repensar a reforma, reformar o pensamento. Rio de Janeiro: Bertrand Brasil; 2004.

6. Lück H. Pedagogia interdisciplinar: fundamentos teóricometodológicos. Petrópolis: Vozes; 2009.

7. Souza DRP, Souza MBB. Interdisciplinaridade: identificando concepções e limites para a sua prática em um serviço de saúde. Rev. Eletr. Enf. [Internet]. 2009 [cited 2011 jun 30];11(1):11723. Available

from:

http://www.fen.ufg.br/revista/v11/n1/v11n1a15.htm.

8. Prado ML, Souza ML, Carraro TE. Investigación cualitativa en enfermería: contexto y bases conceptuales. Washington (Estados Unidos): Organización Panamericana de la Saúde; 2008.

9. Minayo MCS. O desafio do conhecimento: pesquisa qualitativa em saúde. São Paulo: Hucitec; 2007.

10. Strauss A, Corbin J. Pesquisa qualitativa: técnicas e procedimentos para o desenvolvi-mento de teoria fundamentada. Rocha LO, tradutor. Porto Alegre: Artmed; 2008.

11. Ministério da Educação; Conselho Nacional de Educação. Resolução CNE/CES n 3/2001 - Institui Diretrizes Curriculares Nacionais do Curso de Graduação em Enfermagem. Diário Oficial da União (Brasília). 2001 Nov 09.

12. Ferreira Júnior MA. Os reflexos da formação inicial na atuação dos professores enfermeiros. Rev Bras Enferm. 2008;61(6):866-71.

13. Albuquerque VS, Batista RS, Tanji S, Moço ETSM. Currículos disciplinares na área de saúde: ensaio sobre saber e poder. educadores, a capacitação docente ainda é um desafio. Diria que está em estado embrionário, necessitando de um reconhecimento pela instituição de sua necessidade e de sua incorporação no projeto pedagógico da escola e na prática educativa.

Assim, percebe-se que o grande desafio está relacionado a um maior investimento no desenvolvimento profissional do enfermeiro educador, em formação inicial e continuada, munindo-o assim de competências, estratégias e ferramentas que o conduzam a um trabalho mais integrado entre seus saberes científicos e pedagógicos, que possibilitem o diálogo e a articulação com diferentes áreas de conhecimentos, que o tornem mais participativo, para que articule os saberes para o desenvolvimento de competências, contextualizando teoria-prática, visando desenvolver no educando a autonomia, o senso crítico e reflexivo para que possa atuar no mundo do trabalho em constante mudança e vencer o grande desafio: "o cuidar".

Interface (Botucatu) [Internet]. 2009 [cited 2011 jun 30];13(31):261-72. Available from: http://www.scielo.br/pdf/icse/v13n31/a03v1331.pdf.

14. Rodrigues RM, Caldeira S. Formação na Graduação em Enfermagem no Estado do Paraná. Rev Bras Enferm. 2009;62(3):417-23.

15. Moya JLM, Prado ML. El curriculum de enfermería como prototipo de tejné: racionalidad instrumental y tecnológica. Texto Contexto Enferm [Internet]. 2009 [cited 2011 jun 30];18(4):617-26. Available from: http://www.scielo.br/pdf/tce/v18n4/02.pdf.

16. Monteiro S, Vargas E, organizadores. Educação, comunicação e tecnologia educacional: interfaces com o campo da saúde. Rio de Janeiro: Fiocruz; 2006.

17. Fazenda ICA. Interdisciplinaridade: história, teoria e pesquisa. Campinas: Papirus; 2007.

18. Chaves EM, Amorim DMB. A interdisciplinaridade como princípio de formação docente: limites e possibilidades - o CSFP em questão. Educação. 2009;32(3):316-25.

19. Madeira MZA, Lima MGSB. A prática pedagógica das professoras de enfermagem e os saberes. Rev Bras Enferm. 2007;60(4):400-4.

20. Carvalho RS, Viana LO. A formação do enfermeiro docente do ensino médio profissionalizante na relação com o princípio da interdisciplinaridade. Enferm. glob. [Internet]. 2009 [cited 2011 jun 30];(15). Available from: http://scielo.isciii.es/pdf/eg/n15/docencia2.pdf

Artigo recebido em 10.03.2010.

Aprovado para publicação em 27.06.2011.

Artigo publicado em 30.06.2011. 